\title{
Transbrachial approach — taken from the history
}

\author{
Matias Trbušić*, Ivo Darko Gabrić, Hrvoje Pintarić, Ozren Vinter, Tomislav Krčmar, Zdravko Babić \\ University Hospital Centre Sestre milosrdnice, Zagreb, Croatia
}

Purpose: Radial arterial approach has become the default option for coronary procedures in our cath lab (>90\%). However, there are situations when radial arterial approach is not possible (e.g. congenital anomalies, tortuous configurations, radioulnar loop, weak or absent radial pulse secondary to the previous puncture or catheterization). In such situations, a common second-line approach is used (femoral or ulnar). Many clinicians considered transbrachial (TB) angiography as a high-risk and an obsolete procedure. In literature, the complication rate was unacceptably high (up to $36 \%$ ). The aim of this retrospective investigation was to evaluate the safety and efficiency of TB approach as an alternative to radial approach, especially after the unsuccessful radial artery puncture.

Method: During the period of two years, TB coronary angiography in the antecubital region was performed in 25 patients with stable and unstable angina or valvular heart disease. In 12 patients, diagnostic procedure was followed by a coronary intervention. Reasons for TB approach were weak or absent radial pulse (12 cases) or unsuccessful radial artery puncture (13 cases). Procedures were performed by three experienced transradial invasive cardiologists (transradial success more than 95\%). The catheter size was $6 \mathrm{Fr}$

Received: $30^{\text {th }}$ Apr 2014

${ }^{*}$ Address for correspondence: Klinički bolnički centar Sestre milosrdnice, Vinogradska 29, HR-10000 Zagreb, Croatia.

Phone: +385-99-3787-064

E mail: matias.trbusic@gmail.com in all patients. Anticoagulation protocol was used while following the guidelines (aspirin, clopidogrel, unfractionated heparin) but without glycoprotein IIb/IIla receptor inhibitors. Major complications were defined as vascular complications requiring blood transfusion or surgery or permanent neurological deficit in the lower limb. Minor complications were defined as vascular complications not requiring blood transfusion or surgery and transient neurological deficit in the lower limb. A standard post-procedural protocol was the removal of the artery sheath 3 hours after the diagnostic procedure, 6 hours after $\mathrm{PCl}$ and manual puncture site compression for 10 minutes.

Results: Overall success rate was 96\% (24/25). There were no major complications and we noticed only two minor complications (8\%), both hematomas.

Conclusion: TB approach, when used by dedicated transradialists, seems to be easily feasible, safe, and effective. Local vascular complications could be avoided by the cautious and sensitive puncture technique. Other important factors include the use of 6 Fr catheters, defensive anticoagulation and careful observation by the nursing team after the sheath withdrawal. TB approach has all advantages of the arm approach over the femoral (early ambulation, patient preference, suitable for patients with severe occlusive aortoiliac disease and for patients with difficulty when lying down).

KEYWORDS: transbrachial approach, puncture site. CITATION: Cardiol Croat. 2014;9(5-6):178.

\section{Literature}

1. Sabbah MM, Kadota K, Fuku Y, et al. TCT-272 Comparative effectiveness of the different arterial approaches "transbrachial, transradial and transfemoral" in PCl: real-world experiences. J Am Coll Cardiol. 2013;62(18_S1):B89-B89. 